\title{
ORIGINAL ARTICLE \\ Reliability of the Modified Ashworth Scale and Modified Tardieu Scale in patients with spinal cord injuries
}

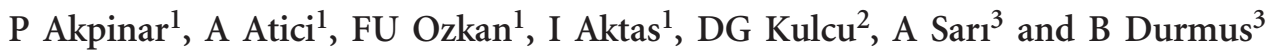

Study design: Psychometrics study.

Objectives: To assess the reliability of the Modified Ashworth Scale (MAS) and Modified Tardieu Scale (MTS) in patients with spinal cord injuries (SCls).

Setting: Inpatient rehabilitation clinics at two state hospitals.

Methods: The study included 65 participants aged between 18 and 88 years with SCl with spasticity. All participants were at least 6 months after injury and had an American Spinal Injury Association Impairment Scale grade of A-D. The MAS and MTS scores were collected from the right hip adductor and hip extensor muscles, right knee extensor and knee flexor muscles and right plantar flexor muscles. Each participant was assessed twice by two experienced physiatrists 1 week apart. The raters were blinded to each other's scores.

Results: Inter-rater and test-retest agreement for the MAS scores $(\kappa=0.531-0.774)$ was moderate to substantial. Inter-rater and test-retest agreement for the MTS $X$ scores $(\kappa=0.692-0.917)$ was substantial to almost perfect. Inter-rater reliability and test-retest reliability of the MTS R2-R1 was excellent (intra-class correlation coefficient (ICC) 0.874-0.973, confidence interval (CI): 0.79-0.98) for all muscles tested. Inter-rater reliability of the MTS R2 for the hip adductor and knee extensor muscles was poor (ICC $0.248, \mathrm{Cl}:-0.00$ to 0.47 and ICC $0.094, \mathrm{Cl}:-0.16$ to 0.34 , respectively). The test-retest reliability of the MTS R2 was also poor for the knee extensor muscles (ICC 0.318, Cl: -0.06 to 0.53 ).

Conclusion: MAS has adequate reliability for determining lower-extremity spasticity in patients with SCl. The demonstration of excellent inter-rater reliability and test-retest reliability of the MTS R2-R1 suggests its utility as a complementary tool for informing treatment decisions in patients with $\mathrm{SCl}$.

Spinal Cord (2017) 55, 944-949; doi:10.1038/sc.2017.48; published online 9 May 2017

\section{INTRODUCTION}

Spasticity is a long-term complication of spinal cord injuries (SCIs). The commonly accepted definition of spasticity is 'a motor disorder characterised by a velocity-dependent increase in tonic stretch reflexes with exaggerated tendon jerks, resulting from hyperexcitability of the stretch reflex' (Lance, ${ }^{1}$ p 485). However, this definition is too narrow for patients with SCI. ${ }^{2}$ The Ability Network, which is an international initiative organised to optimise the management of disabling spasticity following SCI, recommends adoption of the definition proposed by Pandyan: 'disordered sensorimotor control, resulting from an upper motor neuron lesion, presenting as intermittent or sustained involuntary activation of muscles' (Pandyan et al., ${ }^{3}$ p 5; Burns ${ }^{4}$ ). Appropriate diagnosis and assessment of spasticity are recommended for the management of disabling spasticity.

The frequency of spasticity observed among people with SCI varies from $65 \%$ to $78 \%$ in different studies. ${ }^{5-7}$ Self-reported data reveal that $53 \%$ of participants with SCI report spasticity as a significant problem. ${ }^{8}$ Spasticity may be of some benefit in the maintenance of muscle tone; however, it can interfere with daily activities, such as transfers, ambulation and stable body position. A proper evaluation of spasticity is necessary for making treatment decisions.

The Ashworth Scale and Modified Ashworth Scale (MAS) are frequently used clinical scales that assess spasticity. Five studies that have assessed the reliability of the MAS of lower extremities among people with $\mathrm{SCI}^{9-13}$ have presented inconsistent results; so reassessment remains necessary for the MAS for the lower extremity after SCI.

The Tardieu Scale (TS), which quantifies muscle tone at specified velocities, has been suggested as superior to the Ashworth Scale for the assessment of neural versus peripheral contributions of spasticity. ${ }^{14-16}$ The Tardieu Scale, developed by Tardieu et al. ${ }^{17}$ in 1954, was subsequently modified by Held and Peierrot-Deseilligny ${ }^{18}$ to comprise quantitative joint angle measurements taken at three speeds of passive movements-very slow, a passive fall of the limb under the influence of gravity and as fast as possible. In 1999, Boyd and Graham ${ }^{19}$ further modified the scale, by standardising the conditions of limb placement and the speeds as slow and fast, to produce the version presently known as the Modified Tardieu Scale (MTS). They recommended an

${ }^{1}$ Department of Physical Medicine and Rehabilitation, Fatih Sultan Mehmet Education and Research Hospital, Istanbul, Turkey; ${ }^{2}$ Department of Physical Medicine and Rehabilitation, Haydarpasa Numune Education and Research Hospital, Istanbul, Turkey and ${ }^{3}$ Department of Physical Medicine and Rehabilitation, Erenkoy Physical Medicine and Rehabilitation Hospital, Istanbul, Turkey

Correspondence: Dr P Akpinar, Department of Physical Medicine and Rehabilitation, Fatih Sultan Mehmet Education and Research Hospital, Fatih Sultan Mehmet Egitim ve Arastırma Hastanesi, Fiziksel Tip ve Rehabilitasyon Klinigi H blok, Atasehir, Istanbul 34752, Turkiye.

E-mail: pinar.pinarakpinar@gmail.com

Received 19 November 2016; revised 27 March 2017; accepted 29 March 2017; published online 9 May 2017 
initial speed as slow as possible and a high speed as fast as possible. The relative difference between the slow and fast speeds of passive stretch then determined the dynamic component of the muscle contracture.

A review of the published literature indicates that both the Ashworth Scale and the TS have equivocal reliability, although the TS has superior validity and reliability over the Ashworth Scale. ${ }^{14-16,20-23}$ The reliability of the MTS has been established by extensive studies conducted in children with cerebral palsy and in adults with spasticity of cerebral origin. Most studies on the reliability of the TS have involved investigations across a range of upper limb muscles. Ben-Shabat et al. ${ }^{23}$ investigated the intra- and inter-rater reliability of the MTS for the assessment of lower limb spasticity in adults with neurological injuries. They assessed 30 patients but only 3 of those patients had an SCI. No studies have yet utilised a greater number of participants to evaluate the reliability of the MTS for the assessment of lower limb spasticity in SCI.

We aimed to investigate the reliability of the MAS and the MTS for the assessment of lower limb spasticity in people with SCI. We also aimed to compare the reliability of the MAS and the MTS in adults with spasticity due to SCI.

\section{METHODS}

\section{Data collection}

Sixty-five people with SCI, aged 18-88 years, were screened for inclusion from the inpatient rehabilitation clinics of two state hospitals. Six were excluded ( 3 due to early discharge; 3 due to infection) and 1 declined to be involved, leaving a sample of 58 participants.

People were eligible for inclusion if they had an American Spinal Injury Association (ASIA) Impairment Scale Grades of A-D with spasticity and were at least 6 months after injury. All participants' medication was stable with no initiation or dose change of oral antispasticity drug treatment within 30 days, and no botulinum toxin injections administered $<90$ days before the assessment. People were excluded if they had multiple central nervous system lesion sites, significant complications that affect spasticity (such as decubitus ulcers, heterotopic ossification, urinary tract infections and any other infections), known history of joint pain and inability to give informed consent. Informed consent was obtained, and all procedures were conducted in accordance with the Helsinki Declaration of 1975 and approved by the local Institutional Clinical Research Ethics Committee (Fatih Sultan Mehmet Education and Research Hospital). We further certify that all applicable institutional and governmental regulations concerning the ethical use of human volunteers were followed during the course of this research.

\section{Instruments}

The MAS is an easy-to-administer tool, which has been adopted for assessing spasticity in a variety of indications, including SCI. ${ }^{9,24}$ It is a five-point ordinal scale that subjectively assesses muscle tone. The MAS scores were collected from the right hip adductor and extensor muscles, right knee extensor and flexor muscles and right plantar flexor muscles of the participants. Following the recommendations of Pandyan et al., ${ }^{25}$ all participants were assessed while lying supine, with the upper limbs parallel to the trunk in a neutral position and with the lower limbs parallel to one another. One exception was the assessment of knee extensors, which was conducted in the prone position. The rater passively moved each participant's joints through a full range of motion at a stretching velocity standardised by counting 'one thousand and one' and judged the degree of tone. ${ }^{26}$ The rater performed only one movement cycle in flexion and one movement cycle in extension; repetitive cycles were avoided.

The $\mathrm{TS}^{17}$ was introduced in 1954 and further modified, presently known as MTS. ${ }^{19}$ The three key components of the test are as follows: the velocity of stretch, the quality of the muscle reaction, and the angle of the muscle reaction. Based on the suggestions of previous researchers, ${ }^{18,19,27,28}$ the rater first moved the joint as slowly as possible (defined as V1) through its full range of motion. The angle was measured with a universal goniometer by another physiatrist who placed the goniometer near the joints and read the values. The angle of full range of motion was defined as R2. Afterwards, the rater moved the joint as rapidly as possible (defined as V3) in the same direction and through the same full movement arc. The angle of muscle reaction (either a clear catch or clonus) was measured with the goniometer and recorded as R1. The difference between $\mathrm{R} 2$ and $\mathrm{R} 1(\mathrm{R} 2-\mathrm{R} 1)$ reflects the dynamic tone component of spasticity. The larger the spasticity angle, the more spastic the muscle.

The quality of the muscle reaction (the $X$ value) was then rated at V3. A standard $0-5$ scale was used for the qualitative rating of reaction to fast movements. A score of 0 represents no resistance throughout the course of the passive movement. A score of 1 represents a slight resistance throughout the course of stretching without a clear catch at any angle. A score of 2 represents a clear catch occurring at a precise angle, interrupting the passive movement and followed by a release. A score of 3 represents a fatigable clonus $(<10 \mathrm{~s}$, when maintaining the pressure). A score of 4 represents an infatigable clonus ( $>10 \mathrm{~s}$, when maintaining the pressure) occurring at a precise angle. A score of 5 represents an immovable joint. Only one stretch was used at each speed.

\section{Testing protocol and reliability}

The MAS and MTS scores were collected by two experienced physiatrists from the right hip adductor and extensor muscles, right knee extensor and flexor muscles and right plantar flexor muscles of the participants. These physiatrists each had $>5$ years of experience in the assessment of spasticity. To ensure optimal standardisation of the MAS and MTS assessment, they undertook a training session before the initiation of the study.

The participants were first measured with the MAS and then $30 \mathrm{~min}$ later with the MTS. The raters were blinded to the scores of the examinations. Inter-rater reliability was investigated with a 30 -min break between assessments. A third physiatrist performed the goniometric measurements for the MTS. The goniometric measurement protocol for the MTS is shown in Table 1.

Test-retest reliability was investigated by having the first physiatrist retest each participant positioned in the same way as the first test, at the same time of the day, 1 week apart.

\section{Analyses}

Statistical analyses were performed using the IBM SPSS Statistics 22 software package (IBM Turk Limited Company, Istanbul, Turkey). Data are presented as mean \pm s.d. The inter-rater and test-retest agreement of the MAS and MTS $X$ scores (qualitative spasticity ratings) were determined using weighted kappa statistics. ${ }^{29}$ We used the criteria of Landis and Koch to interpret kappa values: $<0.0=$ poor,$\quad 0.00-0.20=$ slight,$\quad 0.21-0.40=$ fair,$\quad 0.41-0.60=$ moderate, $0.61-0.80=$ substantial, and $0.81-1.00=$ almost perfect. ${ }^{30}$ For continuous data such as R1, R2 and R2-R1, the test-retest and inter-rater reliability of angle measurements was determined using an intra-class correlation coefficient (ICC). ${ }^{29,31}$ The ICC values were interpreted as follows: $<0.40=$ poor; $0.40-0.59=$ fair; $0.60-0.74=$ good; and $0.75-1.00=$ excellent $^{32}$ Spearman's rank correlation coefficient was used to identify the relationship between the MAS and the MTS X scores, and Wald test was used to set statistical differences between kappa values.

\section{RESULTS}

The mean (s.d.) age of participants was $44 \pm 14$ years. Twenty-one were females (36\%) and 37 were males (64\%) with a mean (s.d.) time since injury of $49 \pm 60$ months (range: 6-338 months). The characteristics of the study population are given in Table 2 . The total mean (s.d.) score for the Functional Independence Measure was $88 \pm 26$ points.

\section{Inter-rater and test-retest reliability of the MAS}

The inter-rater and test-retest kappa values for MAS are shown in Table 3. The test-retest kappa coefficients ranged from 0.636 to 0.716 and demonstrated substantial agreement $(P<0.01)$, except for the hip adductor muscles. The test-retest kappa coefficient for the hip adductor muscles was 0.580 , indicating moderate agreement 
Table 1 Goniometer measurement protocol of the MTS

\begin{tabular}{|c|c|c|c|c|c|}
\hline \multirow[t]{2}{*}{ Muscle } & \multirow[t]{2}{*}{ Patient position } & \multirow[t]{2}{*}{ Testing procedure } & \multicolumn{3}{|c|}{ Goniometer landmarks } \\
\hline & & & Proximal arm & Centre of the goniometer & Distal arm \\
\hline Hip adductors & Supine, leg in midline & Maximal hip abduction & Between ASISs & Over ASIS & To mid-patella \\
\hline Hip extensors & Supine & $\begin{array}{l}\text { Initially the knee is extended, but flexion is } \\
\text { allowed as hip flexion continues }\end{array}$ & $\begin{array}{l}\text { Lateral midline } \\
\text { of the pelvis }\end{array}$ & $\begin{array}{l}\text { Lateral aspect of the hip, } \\
\text { over greater trochanter }\end{array}$ & $\begin{array}{l}\text { Lateral midline of femur to } \\
\text { femoral lateral epicondyle }\end{array}$ \\
\hline Knee extensors & $\begin{array}{l}\text { Supine, hip in } 90^{\circ} \\
\text { flexion, knee extended }\end{array}$ & Maximal knee flexion & $\begin{array}{l}\text { Greater } \\
\text { trochanter }\end{array}$ & $\begin{array}{l}\text { Over lateral epicondyle of } \\
\text { the femur }\end{array}$ & Lateral malleolus \\
\hline Knee flexors & $\begin{array}{l}\text { Supine, hip in } 90^{\circ} \\
\text { flexion, knee flexed }\end{array}$ & Maximal knee extension & $\begin{array}{l}\text { Greater } \\
\text { trochanter }\end{array}$ & $\begin{array}{l}\text { Over lateral epicondyle of } \\
\text { the femur }\end{array}$ & Lateral malleolus \\
\hline Ankle plantar flexors & $\begin{array}{l}\text { Supine, knee } \\
\text { extended }\end{array}$ & Maximal ankle dorsiflexion & Fibula head & Over lateral malleolus & $\begin{array}{l}\text { Lateral aspect of the fifth } \\
\text { metatarsal }\end{array}$ \\
\hline
\end{tabular}

Abbreviations: ASIS, anterior superior iliac spine; MTS, Modified Tardieu Scale.

$(P<0.01)$. The inter-rater agreement measures for the MAS were slightly lower than those for test-retest agreement, and the kappa values ranged from 0.531 to $0.774 \quad(P<0.01)$ for the two physiatrists. The measurements made by the two physiatrists for the hip adductor, hip extensor muscles and knee extensor muscles showed moderate agreement, and the measurements for the knee extensors and ankle plantar flexor muscles showed substantial agreement.

\section{Inter-rater and test-retest reliability of the MTS}

The kappa coefficients for the MTS $X$ scores (qualitative spasticity ratings) were $0.73-0.82$, indicating substantial agreement. The results are listed in Table 4.

The ICCs for the inter-rater and test-retest reliability are shown in Table 5 and Table 6, respectively. The R2-R1 measurements showed excellent inter-rater reliability for all the muscles tested. The R1 measurements of the right hip adductor, hip extensor muscles, right knee flexor and knee extensor muscles also showed excellent inter-rater reliability, but this reliability was only fair for the ankle plantar flexor muscles. The inter-rater reliability for the R2 measurements varied considerably across muscles, ranging from high (ankle plantar flexor) to good (knee flexor) to fair (hip extensor) to poor (hip adductor, knee extensor).

The R2-R1 measurements showed excellent test-retest reliability for all the muscles tested. The R1 measurements of the right hip adductor, hip extensor muscles and right knee flexor and extensor muscles showed excellent test-retest reliability, but the ankle plantar flexor muscles showed only fair reliability. The test-retest reliability for the R2 measurements varied considerably across muscles, ranging from excellent (hip extensor and ankle plantar flexor) to fair (knee flexor) to poor (knee extensor).

\section{Correlations of the MAS with the MTS X scores}

Figures 1 and 2 show the percentage of participants with different levels of MAS and MTS X grades, respectively. Significant correlations were noted between the MAS and MTS X grades for all the muscles tested (hip adductor muscles, $r$ : 0.791; hip extensor muscles muscles, $r$ : 0.920; knee extensor muscles, $r$ : 0.539; knee flexor muscles, $r: 0.562$; and ankle plantar flexor muscles, $r$ : 0.864 ; all $P<0.01$ ). The differences between the kappa values of MAS and MTS $X$ scores revealed significantly higher test-retest reliability for the MTS than for the MAS with respect to the hip adductor and knee flexor muscles $(Z>1.96 ; P<0.05)$. Inter-rater reliability was significantly higher for the MTS than for the MAS in all the muscle groups $(Z>1.96 ; P<0.05)$, with the exception of the hip adductor and ankle plantar flexor muscles $(Z<1.96 ; P>0.05)$.

\section{DISCUSSION}

This is the first study to investigate the reliability of the MTS and MAS in a large group of people with SCI. Our results demonstrate substantial test-retest agreement of the MAS for all the muscles tested, except for the hip adductor muscles. The MAS scores for the hip adductor, hip extensor and knee extensor muscles showed moderate inter-rater agreement, while the ankle plantar flexor and knee flexor muscle scores showed substantial inter-rater agreement. The inter-rater and test-retest reliability of the R2-R1 and R1 measurements of the MTS were generally excellent, except for the R1 measurements of the ankle plantar flexor muscles, which were fair. The reliability of R2 measurements of the MTS varied from muscle to muscle (that is, the inter-rater reliability of R2 measurements of the hip adductor muscles was poor, and the inter-rater reliability of R2 measurements of the knee flexor muscles was good). The MTS $X$ scores showed substantial inter-rater and test-retest reliability.

Our results demonstrate significant correlations between the MAS and MTS $X$ scores, with a significantly higher reliability for the MTS than for the MAS in some of the lower limb muscles. These findings somewhat support those of Mehrholz et al. ${ }^{21}$ and Waninge et al., ${ }^{22}$ as these researchers showed a superior reliability of the MTS over the MAS.

Important factors that improve reliability are the use of well-trained, experienced testers and standardised user guidelines. When used by well-trained and experienced testers, the MTS has good-to-very-good test-retest reliability, although it shows only limited inter-rater reliability in patients with severe brain injury and impaired consciousness. ${ }^{21}$ Gracies et al., ${ }^{33}$ who conducted a two-phase pretraining and posttraining study of the TS in patients with cerebral palsy, found significantly improved inter-rater and intra-rater reliability after training when measuring elbow flexor and plantar flexor spasticity in children with cerebral palsy. However, they had difficulty in achieving inter-rater reliability for spasticity angle measurements in the knee, even after training. In our study, we ensured optimal standardisation of the MAS and MTS assessments by having our testers undertake a training session before initiation of the study. Nevertheless, we found moderate-to-fair inter-rater reliability of the MAS and MTS R2 for the tested hip and knee 
Table 2 Characteristics of the study population

\begin{tabular}{|c|c|c|}
\hline Characteristics & $n$ & $\%$ \\
\hline \multicolumn{3}{|l|}{ ASIA grade } \\
\hline$A$ & 13 & 22.4 \\
\hline B & 8 & 13.8 \\
\hline C & 16 & 27.6 \\
\hline $\mathrm{D}$ & 21 & 36.2 \\
\hline \multicolumn{3}{|l|}{ ASIA level } \\
\hline Cervical & 18 & 30.9 \\
\hline Thoracal & 29 & 49.8 \\
\hline Lumbosacral & 11 & 18.9 \\
\hline \multicolumn{3}{|c|}{ Time after injury (years) } \\
\hline $0.5-1$ & 11 & 19.0 \\
\hline $1-5$ & 35 & 60.3 \\
\hline $5-10$ & 6 & 10.3 \\
\hline $10-15$ & 2 & 3.4 \\
\hline $15-20$ & 3 & 5.2 \\
\hline$>20$ & 1 & 1.7 \\
\hline \multicolumn{3}{|l|}{ Etiology } \\
\hline Traffic accidents & 12 & 20.7 \\
\hline Violence & 4 & 6.9 \\
\hline Falls & 22 & 37.9 \\
\hline Diving & 2 & 3.4 \\
\hline Tumour/infection & 8 & 15.5 \\
\hline Sports & 9 & 15.5 \\
\hline \multicolumn{3}{|l|}{ Spasticity medication } \\
\hline Baclofen & 18 & 31 \\
\hline Tizanidine & 4 & 6.9 \\
\hline Diazepam & 2 & 3.4 \\
\hline
\end{tabular}

Abbreviation: ASIA, American Spinal Injury Association.

muscles. This could be due to the inherent difficulties maintaining the position of the paralysed lower limbs of participants with SCI, regardless of training or experience. For example, it is difficult to perform rapid knee extension in these individuals. Moreover, MTS might not be as sensitive in the proximal muscle groups of the lower extremities or the clonus might not be as common in the proximal joint muscles of patients with SCI as seen in our study population (Figure 2).

By contrast, we found excellent inter-rater and test-retest reliability of R2-R1 and R1 measurements of the MTS (except R1, measurements of the ankle plantar flexor muscles were fair). These measurements have important clinical implications; for example, the $\mathrm{R} 2-\mathrm{R} 1$ value indicates the level of spasticity in the joint. Differentiation of spasticity and muscle contracture is important before a treatment decision is made. Based on the excellent inter-rater and test-retest reliability of R2-R1 shown by our results, we suggest that MTS may serve as a reliable and useful tool for deciding the treatment plan in patients with SCI.

The MAS is still the most widely used clinical measurement of spasticity in clinical settings. ${ }^{6}$ However, studies that have examined the reliability of the MAS of lower extremities among patients with SCI have yielded conflicting results. ${ }^{9,10-11}$ For example, Craven and Morris $^{12}$ found an inadequate reliability for the MAS for determining lower extremity spasticity between raters or over time (inter-session). By contrast, Baunsgaard et al. ${ }^{13}$ demonstrated an acceptable reliability
Table 3 Inter-rater and test-retest agreement of the MAS

\begin{tabular}{lll}
\hline MAS scores & Inter-rater agreement & Test-retest agreement \\
\cline { 2 - 3 } & \multicolumn{2}{c}{ Kappa } \\
\hline Hip adductor muscles & $0.580^{* *}$ & $0.580^{* *}$ \\
Hip extensor muscles & $0.574^{* *}$ & $0.716^{* *}$ \\
Knee flexor muscles & $0.607^{* *}$ & $0.636^{* *}$ \\
Knee extensor muscles & $0.531^{* *}$ & $0.644^{* *}$ \\
Ankle plantar flexor muscles & $0.774^{* *}$ & $0.682^{* *}$ \\
\hline
\end{tabular}

Abbreviation: MAS, Modified Ashworth Scale.

** Significant at $P<0.01$.

Table 4 Inter-rater and test-retest agreement of the MTS $X$ scores

\begin{tabular}{lll}
\hline MTS X scores & Inter-rater agreement & Test-retest agreement \\
\cline { 2 - 3 } & \multicolumn{2}{c}{ Kappa } \\
\hline Hip adductor muscles & $0.692^{* *}$ & $0.805^{* *}$ \\
Hip extensor muscles & $0.876^{* *}$ & $0.825^{* *}$ \\
Knee flexor muscles & $0.860^{* *}$ & $0.917^{* *}$ \\
Knee extensor muscles & $0.746^{* *}$ & $0.752^{* *}$ \\
Ankle plantar flexor muscles & $0.768^{* *}$ & $0.838^{* *}$ \\
\hline
\end{tabular}

Abbreviation: MTS, Modified Tardieu Scale.

** Significant at $P<0.01$.

for the MAS and recommended repeated measures by the same rater when possible. Our test-retest reliability was substantial for the MAS for all the muscles tested, except for the hip adductor muscles. The test-retest reliability of the hip adductor muscles and the inter-rater reliability of the hip adductor, hip extensor and knee extensor muscles were moderate. The knee flexor and ankle plantar flexor muscles showed substantial inter-rater reliability. Therefore, the MAS could be used reliably for the assessment of spasticity in the lower extremity of patients with SCI. We also recommend assessment by the same rater when possible, as the test-retest reliability was higher than the inter-rater reliability.

One limitation of our study was that, although a 30-min break was imposed between assessments of inter-rater reliability, the preceding test could still have affected the subsequent test. Another limitation is that all our testers were experienced physiatrists, so our results may not be generalisable to less experienced testers or different health professionals (therapists, nurses and so on).

The multidimensional nature of spasticity has also been put forward as a consideration when selecting outcome measures for spasticity. ${ }^{9}$ Patients with SCI often experience exaggerated muscle reflex responses, such as clonus, flexor spasms and extensor spasms. The Spinal Cord Assessment Tool for Spastic Reflexes, developed by Benz et al. ${ }^{34}$ is suggested as a valid and reliable tool for assessment of spasm activity in patients with SCI. ${ }^{35}$ Spasticity intervention trials should also include objective, subjective and functional assessments. ${ }^{36}$ Hence, a combination of tools is needed for effective evaluation, treatment and management of spasticity in patients with SCI. The MAS is an easy-to-administer tool, and the MTS is a good tool for assessing peripheral contributions of spasticity. Our results also demonstrate that MAS and MTS have adequate reliability for determining lower-extremity spasticity in patients with SCI, indicating that these scales may serve as complementary tools for functional assessments to decide the best treatment options for patients with SCI. 
ICC $(95 \% \mathrm{Cl})$

\begin{tabular}{|c|c|c|c|}
\hline & & & \\
\hline Hip adductor muscles & $0.809(0.69 \text { to } 0.88)^{* *}$ & $0.248(-0.00 \text { to } 0.47)^{*}$ & $0.973(0.95 \text { to } 0.98)^{* *}$ \\
\hline Hip extensor muscles & $0.958(0.93 \text { to } 0.97)^{* *}$ & $0.578(0.37 \text { to } 0.72)^{* *}$ & $0.951(0.91 \text { to } 0.97)^{* *}$ \\
\hline Knee extensor muscles & $0.764(0.63 \text { to } 0.85)^{* *}$ & $0.094(-0.16$ to 0.34$)$ & $0.874(0.79 \text { to } 0.92)^{* *}$ \\
\hline Ankle plantar flexor muscles & $0.454(0.22 \text { to } 0.64)^{* *}$ & $0.804(0.68 \text { to } 0.88)^{* *}$ & $0.911(0.85 \text { to } 0.94)^{* *}$ \\
\hline
\end{tabular}

Abbreviations: $\mathrm{Cl}$, confidence interval; ICC, intra-class correlation coefficient; MTS, Modified Tardieu Scale.

** Significant at $P<0.01$, * Significant at $P<0.05$.

Table 6 Test-retest reliability of the MTS R1, R2 and R2-R1

\begin{tabular}{|c|c|c|c|}
\hline & \multicolumn{3}{|c|}{ ICC (95\% Cl) } \\
\hline & $R 1$ & $R 2$ & $R 2-R 1$ \\
\hline Hip adductor muscles & $0.796(0.67-0.87)^{* *}$ & $0.637(0.45-0.76)^{* *}$ & $0.934(0.89-0.96)^{* *}$ \\
\hline Hip extensor muscles & $0.929(0.88-0.95)^{* *}$ & $0.937(0.97-0.99)^{* *}$ & $0.894(0.82-0.93)^{* *}$ \\
\hline Knee flexor muscles & $0.943(0.90-0.96)^{* *}$ & $0.451(0.22-0.63)^{* *}$ & $0.962(0.93-0.97)^{* *}$ \\
\hline Knee extensor muscles & $0.910(0.85-0.94)^{* *}$ & $0.318(0.06-0.53)^{* *}$ & $0.914(0.85-0.94)^{* *}$ \\
\hline Ankle plantar flexor muscles & $0.494(0.26-0.66)^{* *}$ & $0.876(0.79-0.92)^{* *}$ & $0.912(0.85-0.94)^{* *}$ \\
\hline
\end{tabular}

Abbreviations: $\mathrm{Cl}$, confidence interval; ICC, intra-class correlation coefficient; MTS, Modified Tardieu Scale.

** Significant at $P<0.01$.

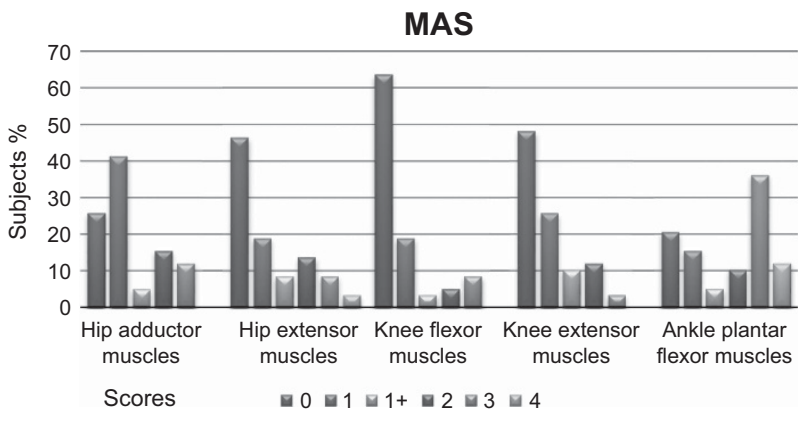

Figure 1 The percentage of participants with scores of 0-4 on the MAS. The figure shows the distribution of the MAS scores based on the location of the muscle group. The vertical axis shows the percentages of the participants. A full colour version of this figure is available at the Spinal Cord journal online.

\section{CONCLUSIONS}

Our study findings indicate moderate-to-substantial inter-rater reliability and test-retest reliability for the MAS. The MAS can therefore be used reliably in spasticity measurements of the lower extremities of people with SCI. Owing to the higher test-retest reliability than the inter-rater reliability, we suggest assessment by the same rater if possible.

Although the MTS R2 showed poor inter-rater reliability for the hip adductor and knee extensor muscles and poor test-retest reliability for the knee extensor muscles, the MTS R2-R1 showed excellent inter-rater reliability and test-retest reliability for all the muscles tested. Thus the MTS may serve as a complementary tool for deciding the treatment plans for people with SCI.

\section{DATA ARCHIVING}

There were no data to deposit.

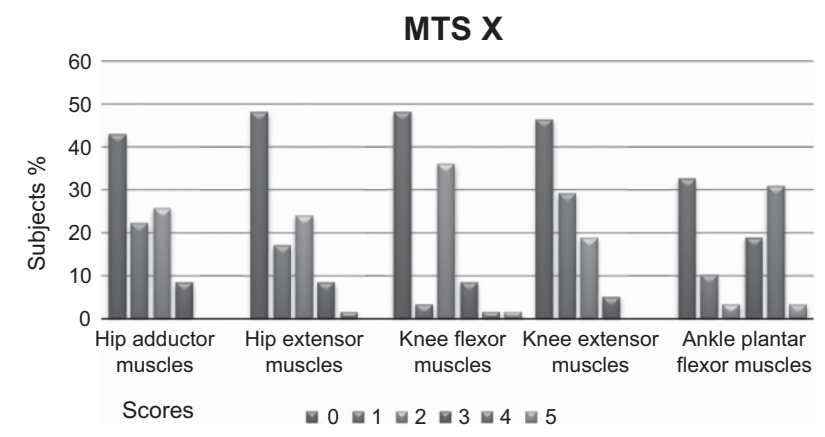

Figure 2 The percentage of participants with scores of $0-5$ on the MTS $X$. The figure shows the different scores of the MTS $X$ with different colours. The vertical axis shows the percentages of the participants. A full colour version of this figure is available at the Spinal Cord journal online.

\section{CONFLICT OF INTEREST}

The authors declare no conflict of interest.

\section{ACKNOWLEDGEMENTS}

We thank the participants of this study.

1 Lance JW. Symposium synopsis. In: Feldman RG, Young PR, Koella WP (eds). Spasticity: Disordered Motor Control. Yearbook Medical Publishers: Chicago, IL, USA, 1980, pp 485-494.

2 Fleuren JF, Voerman GE, Snoek GJ, Nene AV, Rietman JS, Hermens HJ. Perception of lower limb spasticity in patients with spinal cord injury. Spinal Cord 2009; 47: 396-400.

3 Pandyan AD, Gregoric M, Barnes MP, Wood D, Van Wijck F, Burridge J et al. Spasticity: clinical perceptions, neurological realities and meaningful measurement. Review. Disabil Rehabil 2005; 27: 2-6.

4 Burns AS, Lanig I, Grabljevec K, New PW, Bensmail D, Ertzgaard P et al. Optimizing the management of disabling spasticity following spinal cord damage-The Ability Networkan international initiative. Arch Phys Med Rehabil 2016; 97: 2222-2228 
5 Maynard FM, Karunas RS, Waring WP. Epidemiology of spasticity following traumatic spinal cord injury. Arch Phys Med Rehabil 1990; 71: 566-569.

6 Sköld C, Levi R, Seiger A. Spasticity after traumatic spinal cord injury: nature, severity, and location. Arch Phys Med Rehabil 1999; 80: 1548-1557.

7 Hitzig SL, Tonack M, Campbell KA, McGillivray CF, Boschen KA, Richards K et al. Secondary health complications in an aging Canadian spinal cord injury sample. Am J Phys Med Rehabil 2008; 87: 545-555.

8 Walter JS, Sacks J, Othman R, Rankin AZ, Nemchausky B, Chintam R et al. A database of self-reported secondary medical problems among VA spinal cord injury patients: its role in clinical care and management. J Rehabil Res Dev 2002; 39: 53-61.

9 Haas BM, Bergström E, Jamous A, Bennie A. The inter rater reliability of the original and of the modified Ashworth scale for the assessment of spasticity in patients with spinal cord injury. Spinal Cord 1996; 34: 560-564.

10 Smith AW, Jamshidi M, Lo SK. Clinical measurement of muscle tone using a velocitycorrected modified Ashworth scale. Am J Phys Med Rehabil 2002; 81: 202-206.

11 Tederko P, Krasuski M, Czech J, Dargiel A, Garwacka-Jodzis I, Wojciechowska A. Reliability of clinical spasticity measurements in patients with cervical spinal cord injury. Ortop Traumatol Rehabil 2007; 9: 467-483.

12 Craven BC, Morris AR. Modified Ashworth scale reliability for measurement of lower extremity spasticity among patients with SCl. Spinal Cord 2010; 48: 207-213.

13 Baunsgaard CB, Nissen UV, Christensen KB, Biering-Sørensen F. Modified Ashworth scale and spasm frequency score in spinal cord injury: reliability and correlation. Spinal Cord 2016; 54: 702-708.

14 Patrick E, Ada L. The Tardieu Scale differentiates contracture from spasticity whereas the Ashworth Scale is confounded by it. Clin Rehabil 2006; 20: 173-182.

15 Fleuren JF, Voerman GE, Erren-Wolters CV, Snoek GJ, Rietman JS, Hermens HJ et al. Stop using the Ashworth Scale for the assessment of spasticity. J Neurol Neurosurg Psychiatry 2010; 81: 46-52.

16 Haugh AB, Pandyan AD, Johnson GR. A systematic review of the Tardieu Scale for the measurement of spasticity. Disabil Rehabil 2006; 28: 899-907.

17 Tardieu G, Shentoub S, Delarue R. A la recherche d'une technique de measure de la spasticité. Revue de Neurologie (Paris). [Research on a technique for measurement of spasticity]. Rev Neurol (Paris) 1954; 91: 143-144.

18 Held JP, Pierrot-Deseilligny E. Reeducation Motrice des Affections Neurologiques. JB Bailiere et Fils: Paris, France, 1969, pp 31-42.

19 Boyd R, Graham H. Objective measurement of clinical findings in the use of botulinum toxin type A for the management of children with cerebral palsy. Eur J Neurol 1999. 6 : S23-S35.

20 Alhusaini AA, Dean CM, Crosbie J, Shepherd RB, Lewis J. Evaluation of spasticity in children with cerebral palsy using Ashworth and Tardieu Scales compared with laboratory measures. J Child Neurol 2010; 25: 1242-1247.

21 Mehrholz J, Wagner K, Meissner D, Grundmann K, Zange C, Koch R et al. Reliability of the Modified Tardieu Scale and the Modified Ashworth Scale in adult patients with severe brain injury: a comparison study. Clin Rehabil 2005; 19: 751-759.
22 Waninge A, Rook RA, Dijkhuizen A, Gielen E, van der Schans CP. Feasibility, test-retest reliability, and interrater reliability of the Modified Ashworth Scale and Modified Tardieu Scale in persons with profound intellectual and multiple disabilities. Res Dev Disabil 2011; 32: 613-620.

23 Ben-Shabat E, Palit M, Fini NA, Brooks CT, Winter A, Holland AE. Intra- and interrater reliability of the Modified Tardieu Scale for the assessment of lower limb spasticity in adults with neurologic injuries. Arch Phys Med Rehabil 2013; 94 2494-2501.

24 Hsieh JT, Wolfe DL, Miller WC, Curt A, SCIRE Research Team. Spasticity outcome measures in spinal cord injury: psychometric properties and clinical utility. Spinal Cord 2008; 46: 86-95.

25 Pandyan AD1, Johnson GR, Price $\mathrm{Cl}$, Curless RH, Barnes MP, Rodgers $\mathrm{H}$. A review of the properties and limitations of the Ashworth and modified Ashworth Scales as measures of spasticity. Clin Rehabil 1999; 13: 373-383.

26 Bohannon RW, Smith MB. Interrater reliability of a modified Ashworth scale of muscle spasticity. Phys Ther 1987; 67: 206-207.

27 Fosang AL, Galea MP, McCoy AT, Reddihough DS, Story I. Measures of muscle and joint performance in the lower limb of children with cerebral palsy. Dev Med Child Neurol 2003; 45: 664-670.

$28 \mathrm{Li} \mathrm{F}, \mathrm{Wu}$ Y, Li X. Test-retest reliability and inter-rater reliability of the Modified Tardieu Scale and the Modified Ashworth Scale in hemiplegic patients with stroke. Eur J Phys Rehabil Med 2014; 50: 9-15.

29 Yam WKL, Leung MSM. Interrater reliability of Modified Ashworth Scale and Modified Tardieu Scale in children with spastic cerebral palsy. J Child Neurol 2006; 21 1031-1035.

30 Landis JR, Koch GG. The measurement of observer agreement for categorical data. Biometrics 1977; 33: 159-174.

31 Portney LG, Watkins MP. Statistical measures of reliability. In: Portney LG, Watkins MP (eds). Foundations of Clinical Research: Applications to Practice. Prentice-Hall: Upper Saddle River, NJ, USA, 2000, pp 557-586.

32 Cicchetti DV. Guidelines, criteria, and rules of thumb for evaluating normed and standardized assessment instruments in psychology. Psychol Assessment 1994; 6: 284-290.

33 Gracies JM, Burke K, Clegg NJ, Browne R, Rushing C, Fehlings D et al. Reliability of the Tardieu Scale for assessing spasticity in children with cerebral palsy. Arch Phys Med Rehabil 2010; 91: 421-428.

34 Benz EN, Hornby TG, Bode RK, Scheidt RA, Schmit BD. A physiologically based clinical measure for spastic reflexes in spinal cord injury. Arch Phys Med Rehabil 2005; 86: 52-59.

35 Akpinar P, Atici A, Ozkan FU, Aktas I, Kulcu DG, Kurt KN. Reliability of the spinal cord assessment tool for spastic reflexes. Arch Phys Med Rehabil (e-pub ahead of print 12 October 2016; doi:10.1016/j.apmr.2016.09.119).

36 Priebe M. Assessment of spinal cord injury spasticity in clinical trials. Top Spinal Cord Inj Rehabil 2006; 11: 69-77. 